\title{
Southeastern States
}

National Cancer Institute

\section{Source}

National Cancer Institute. Southeastern States. NCI Thesaurus. Code C43448.

The area in the United States comprised of the following states: Tennessee, Georgia, Florida, Alabama and Mississippi. 